\title{
The study of social representations in children and adolescents: Lessons from a review of the literature
}

Marie-Anastasie Aim. Aix-Marseille University. Véronique Goussé. Nîmes University. Thémistoklis Apostolidis. Aix-Marseille University. Lionel Dany. Aix-Marseille University.

\begin{abstract}
An ad hoc review of the existing literature concerning the study of social representations (SRs; Moscovici, 1961/1976) in children and adolescents was conducted in order to put forward theoretical and methodological proposals on the study and development of SRs, and to highlight future directions. The review was performed using the PsycINFO database (up to September 2016), and included 60 eligible works. While the main part of the work sample does not mention theoretical and/or methodological implications (41.7\%), other contributions highlight the necessity to take into account: (a) the active role of children/adolescents as well as their social interactions in the creation of SRs, (b) the relevance of studying SRs in these populations for developing the theory of SRs, (c) the expression of SRs in children's everyday actions, (d) the use of suitable methods for children/adolescents, and (e) the link between the psychology of development and the theory of SRs.
\end{abstract}

Keywords: children; adolescents; social representations; review of the literature.

\section{Resumo}

O estudo das representações sociais entre crianças e adolescentes: Lições de uma revisão de literatura. Foi realizada uma revisão da literatura existente sobre o estudo das representações sociais (RSs; Moscovici, 1961/1976) em crianças e adolescentes com a finalidade de apresentar propostas teóricas e metodológicas para o estudo do desenvolvimento das RSs, e de apontar futuras direções. Realizada a partir da base de dados PsycINFO (até setembro 2016) esta revisão incluiu 60 trabalhos. Enquanto a maior parte dos trabalhos analisados não menciona as suas implicações teóricas e/ou metodológicas (41,7\%), outras contribuições salientam a necessidade de se considerar: (a) o papel ativo das crianças/adolescentes, assim como as suas interações sociais na elaboração de RSs; (b) a relevância de se estudar as RSs destas populações para o desenvolvimento da teoria das RSs; (c) a expressão das RSs nas ações cotidianas de crianças; (d) o uso de métodos adaptados à população de crianças/adolescentes e (e) a relação entre a psicologia do desenvolvimento e a teoria das RSs. Palavras-chave: crianças; adolescentes; representações sociais; revisão de literatura.

\section{Resumen}

El estudio de las representaciones sociales de niños y adolescentes: Enseñanzas de una revista de literatura. Una revista ad hoc de la literatura sobre el estudio de las representaciones sociales (RS; Moscovici, 1961/1976) de los niños y adolescentes ha sido realizada para profundizar las proposiciones teóricas y metodológicas de los estudios del desarrollo de las RSs, y para favorecer futuras orientaciones. Apoyándose en la plataforma PsycINFO (hasta septiembre de 2016), esta revista cuenta 60 investigaciones elegibles. La mayor parte de esos trabajos no evocan las consecuencias teóricas y/o metodológicas (41,7\%). Pero otras contribuciones subrayan la necesidad de tomar en cuenta: (a) el papel activo de los niños/adolescentes, tanto como sus interacciones sociales, en la elaboración de la RSs, (b) la relevancia de estudiar las RSs de esas poblaciones para desarrollar la teoría de las RSs, (c) la expresión de las RSs en las acciones cotidianas de los niños, (d) el uso de metodologías adecuadas para niños/adolescentes, y (e) el vínculo entre la psicología del desarrollo y la teoría de las RSs. Palabras clave: niños; adolescentes; representaciones sociales; revista de literatura. 
For more than 50 years, the theory of Social Representations (SRs) introduced by Serge Moscovici (1961/1976) has established a particularly heuristic and important paradigm in the field of social psychology (e.g., Abric, 1994; Jodelet, 1989; Jovchelovitch, 2007; Lloyd \& Duveen, 1992; Moscovici, 2001; Wagner \& Hayes, 2005). SRs constitute a particular modality of knowledge, generally qualified as common sense knowledge. SRs can be seen as a useful paradigm in the study of social thought. Moscovici (1973) defined SRs as a:

system(s) of values, ideas and practices with a twofold function; first, establish an order which will enable individuals to orient themselves in their material and social world and to master it; secondly to enable communication among the members of a community by providing them codes for social exchange and a code for naming and classifying unambiguously the various aspects of their world and their individual and group history (p. xiii). SRs could be defined as a "form of knowledge that is socially developed and shared, having a practical aim and contributing to the construction of a reality common to a social body" (Jodelet, 1989, p. 53).

One of the major purposes of SRs was originally focused on processes of transformation/ genesis and development. In his work on SRs of psychoanalysis, Moscovici (1961/1976) postulated that the "new" is constructively understood in terms of the "old" and suggests that the emergence of SRs is due to a new situation, a phenomenon or a new or unusual event. Although numerous studies on SRs have been done during the last decades, a minority of them attempted to develop a theoretical background concerning the genesis of SRs (e.g., Duveen \& Lloyd, 1990; Moscovici \& Duveen, 2000; Wagner \& Hayes, 2005). Rouquette and Garnier (1999) underlined the paucity of research on the mechanisms of SRs production. The genesis of SRs could be considered in an individual or collective sense. This genesis can be thought of in terms of appropriation (when the object pre-exists) as well as in terms of construction (when it concerns a "new" object).

The childhood and adolescent age periods are characterized as periods of social development and are particularly relevant for the study of the genesis and the transformation of SRs. Moscovici (1998) discussed Piaget's and Vygotsky's theoretical positions concerning this assertion. Piaget considered that the "prelogical" representations of young children evolve continuously until they reach the representations of adolescents, which are more logical and individual. As for Vygotski and Luria, they supposed an intermittent evolution of collective representations (cf. Durkheim, 1898/1967) and considered that the superior mental process takes its origin in the social field. For Moscovici, these different epistemological perspectives do not permit to apprehend how the "cognitive" is regulated by the social. During this period of construction of the "common sense", the representations emerge and are transformed dynamically and continuously (cf. Löfdahl \& Hägglund, 2006). According to Moscovici (1995), both kinds of representations present in the social environment (sociogenesis) and in the individual environment (ontogenesis) compete with each other during the whole period of child development. Children and adolescents live in a psychosocial environment already structured by SRs of their own group. During their development, children internalize the pre-existing representations. This internalization of SRs allows them to become competent and active social players within their social groups (e.g., Duveen \& Lloyd, 1990). Furthermore, "the circulation of representations around the child does not imply their simple appropriation by the child. Rather, their acquisition is the outcome of a process of development" (Duveen, 1996, p. 256). The assessment of childhood and adolescence constitutes a heuristic way of studying the structuring processes of SRs and their transformation. These specific periods can be typical situations for the study of the joint between system and metasystem, between the cognitive and the social in an explicit manner (Doise, 1988).

In order to put forward theoretical and methodological proposals, and to highlight future directions for the study of SRs in children and adolescents, this contribution aims to perform an ad hoc review of the existing literature on the study of SRs in these populations.

\section{Method}

\section{Search Strategy}

Computerized search was performed using PsycINFO database (up to September 2016). The search strategy was developed taking into consideration the studied population (i.e., children and adolescents). A Boolean search was realized with the following keywords: «social representation AND children», "social representation AND adolescents», and "social representation AND development». The keyword "development" was used to identify works on the sociogenesis of SRs (e.g., Duveen, 1996; Duveen \& Lloyd, 1990). The search was restricted 
to the keywords appearing in the subject terms. Each reference was screened for relevance by studying the title and the abstract.

\section{Selection Criteria}

A set of inclusion criteria was developed for this review: (1) the study had to be published in English or in French, (2) the study had to refer to the SRs theory in an explicit way, (3) the studied population had to include at least one sub-sample of children (with a limit of 3 years old). The age limit was selected according to the children's developmental period by the parameters of the grown-up language (Karmiloff-Smith, 1979) and to the children's acquisition of a representational theory-of-mind (Perner, 1991). The reviewers read the abstract of the references included in the first selection to judge them for inclusion/ exclusion following the inclusion criteria. If the abstract of a study was not available or did not allow for judging its relevance, the research was excluded.

\section{Data Synthesis}

Data extracted from included studies were divided into four categories: (1) population: sample(s) description and country, (2) SRs object studied and aim of the study, (3) method(s), and (4) theoreticalmethodological implications on the study of SRs in children and adolescents.

\section{Results}

\section{Search Results and Study Selection}

The literature search from PsycINFO resulted in the identification of 273 references. The inclusion criteria were applied and references were selected by the title, then by the abstract and finally by the content. First, by reading the titles and the abstracts we excluded duplicate references $(n=93)$, references that did not directly refer to the SRs theory $(n=97)$ and to the studied population $(n=12)$. References that we were not able to find were also excluded $(n=4)$. After that initial screening, the reading of the full articles allowed us to exclude those who did not specifically refer to SRs among children and/ or adolescents $(n=7)$. After following these procedures, $60(22.0 \%)$ references got included.

\section{Study Characteristics}

The references included in the review $(n=60)$ were published during 1987-2016, 19 were published during 1987-2000 and forty-one during 2001-2015 ( median period $=2005$ ).
Population. Concerning the characteristics of the studied populations, the findings showed that the majority of studies studied child ( $n=18 ; 30.0 \%$ ) or adolescent ( $n=17 ; 28.3 \%$ ) samples. Moreover, a small proportion of studies $(n=3 ; 5.0 \%)$ used child and adolescent samples whereas $18.3 \%$ used adolescent and adult samples $(n=11)$, and $10.0 \%(n=6)$ included child, adolescent and adult samples.

In the majority of studies ( $n=33 ; 55.0 \%$ ) both sexes are represented, sometime they deal with only one gender $(n=6 ; 10.0 \%)$ and sometimes gender is not indicated $(n=13 ; 21.6 \%)$ or not pertinent $(n=8 ; 13.3 \%)$.

According to age, the child and adolescent categories were defined differently: child is defined as being aged between 3-14 years or 8-13 years, adolescent as aged between $12-18$ years, $13-18$ years or 11-20 years.

Thirty-six studies were led in one country, 34 were led in Europe: 12 in France (FR), 9 in Italy (IT), 8 in Great Britain (GB), 3 in Sweden (SE), 1 in Greece (GR), and 1 in Denmark (DK). Eight studies were led in America: 6 in Brazil (BR), 1 in the United States (US), and 1 in Canada (CA). Furthermore, 1 was led in Zambia (ZM), and 1 in Australia (AU). Concerning the studies which were led in two countries $(n=4)$, they proposed a comparison between FR and IT, GB and Bosnia (BA), $\mathrm{GB}$ and Argentina (AR), and Finland (FI) and Russia (RU). For the studies that were conducted in more than three countries, we have (a) RU, Georgia (GE), and Ukraine (UA); (b) Costa Rica (CR), FR, IT, and Switzerland (CH); (c) BR, Germany (DE), Mexico, and Romania; (d) GB, US, DE, Netherlands, Poland, and Spain; (e) Senegal Burkina Faso, South East Nigeria, Kenya, Namibia, and Swaziland; ( $f$ ) and a study conducted on participants from 34 countries through an international association.

Moreover, 6 chapters and articles without empirical data (i.e., theoretical-methodological considerations) were included.

SRs objects and aim. The objects of SRs studied in the research can be divided into seven big families: (a) health, illness and risk behaviours ( $n=20$; i.e., health and disease, violence, bullying and aggressive tendencies, poverty, food, and radioactivity); (b) society, law, politics, and economy ( $n=13$; i.e., human and children's rights, war and peace, politics, the euro, the district of Brixton in London, rural and city objects, ideal neighbourhood, public sphere, and the Australian society); (c) skills and capacities ( $n=7$; i.e., learning, reading, and intellectual competences and intelligence); (d) identity ( $n=6$; i.e., national identity, socio-cultural identity and its 
development, men and women drivers, elderly people and old age, and gender); (e) social relationships and their stakes ( $n=6$; i.e., social participation and power, relational modes among peers, robot, happiness and life satisfaction, and the "bistrot"); and (f) work $(n=2)$.

Besides, the subjects chapters and articles of reflection $(n=6)$ deal with a preliminary reflection about (a) the approach to the socio-moral development drawing upon the conceptual framework of SRs; (b) how does a distinctive research strategy emerge from a theory; (c) a socio-constructionist approach to youth and adolescence; (d) reflections about the development of SRs; (e) the impact of communication on gender and cognitive developments; (f) and a critical comparison between developmental social cognitions, and SRs as well as the importance of the developmental approach to the study of SRs.

Method. As regards the methods, 28 studies used just one method: 17 studies used questionnaire(s), seven used interview, eight used free associations task (FAT), two used focus groups, one study used observation, one used drawing with written explanations, and two used short film scenarios.

Nine studies used a combination of two methods, four studies used questionnaire and interview, two used drawing and interview, one used FAT and questionnaires, two used FAT and association task (i.e., pair association task, incomplete sentence), one used FAT and focus groups, and 1 used FAT and interview.

Three studies used three methods, one used observation, task performance and interviews, one used ethnographic observation, structured observation and interviews, and two used observation, drawing and interview. Finally, two studies used four methods, one used FAT, interview, drawing and questionnaire, and the other used drawing, FAT and interview or questionnaire.

a) Among the 18 studies based merely on samples of children (i.e., 3-14years old), six used questionnaire, four used interview, one used observation, one used drawing, one article of two studies used drawing and interview, one used observation, task performance and interview, one used ethnographic observation, structured observation and interview, one article of two studies used FAT and pair association task and drawing and interview, and two study used observation, interview and drawing. Among these studies, five were longitudinal, two was multi-cultural, eight used several samples of children categorized by age, and one was longitudinal and used several samples of children categorized by age.

b) Sixteen research samples only consisted of adolescents (i.e., 11-20 years old), five of them used questionnaire, two used focus groups, four used FAT, two used interview and questionnaire, one used focus groups and FAT, one used FAT, interview, drawing and questionnaire, one used FAT and questionnaire. Among these studies, one is a multi-cultural study and has several samples of adolescents, one is both multi-cultural and longitudinal, and one has several samples of adolescents.

c) Four studies considered samples of children and adolescents. One study used interview, one used a questionnaire, one used short film scenarios, and one used drawing, FAT and interview or questionnaire. Two are multi-cultural, and two has several samples of children/adolescents.

d) Eleven studies considered samples of adolescents (i.e., 12-18 years old) and adults. Four used questionnaire, two used interview, three used FAT, 1 used a SRs scale, and one used association task and FAT. Among these studies, one is a longitudinal study, one is a multi-cultural study, one included the adolescents' parents, and one used several samples of adolescents.

e) Among the five studies with samples of children (i.e., 8-13 years old), adolescents (i.e., 13-18 years old) and adults, one used FAT, one used FAT and interview, one used short film scenarios, and two used questionnaire and interview. Two of these three studies included the children's and adolescents' parents and 1 used several samples of adolescents.

Theoretical-methodological implications. The included works highlight the effect of some variables on SRs: (a) age ( $n=23 ; 38.3 \%)$; (b) practices and behaviours ( $n=18$; $30.0 \%$ ); (c) gender ( $n=14 ; 23.3 \%$ ); (d) social context ( $n=11 ; 18.3 \%$ ); (e) culture ( $n=10$; 16.7\%); (f) family/socio-economic and professional status of parents ( $n=7 ; 11.7 \%$ ); and (g) social norms/ ideological orientation ( $n=4 ; 6.7 \%)$.

Concerning the remarks, the majority of the studies make no mention of theoretical implications (TI) and/or methodological implication (MI) associated with the study of SRs in children and adolescents ( $n=$ 25; 41.7\%) (see Table 1). 
The study of social representations in children and adolescents: Lessons from a review of the literature

Table 1. Characteristics of Works which Make no Mention of Theoretical Implications (TI) or Methodological Implication (MI) Associated to the Study of Srs in Children and/or Adolescents.

\begin{tabular}{|c|c|c|c|c|}
\hline Reference & Population $^{\mathrm{a}}$ & Object & Method $^{b}$ & Design $^{c}$ \\
\hline Beres et al. (2013) & $\mathrm{C} ; \mathrm{A} ; \mathrm{Ad}$ & HIV/AIDS & SFS & TS \\
\hline Bonomo (2013) & $\mathrm{C} ; \mathrm{A} ; \mathrm{Ad}$ & Rural and city & FAT; I & TS \\
\hline Camargo (2003) & C; A & Condoms & SFS & TS \\
\hline Camargo \& Bousfield (2009) & A & Unprotected sex & $\mathrm{Q}$ & TS \\
\hline Carvalho (2013) & A & Learning & Q & TS \\
\hline Carvalho \& de Andrade (2013) & A & Learning & Q & TS \\
\hline Clémence et al. (1995) & $\mathrm{A} ; \mathrm{Ad}$ & Human rights & Q & TS \\
\hline Degreave et al. (2015) & $\mathrm{A} ; \mathrm{Ad}$ & Men and women drivers & Q & TS \\
\hline Dufort et al. (2005) & A & Pregnancy & FAT; FG & TS \\
\hline Ecalle (1997) & C & The reading & Q & TS \\
\hline Fortunati et al. (2015) & C; A & Robots & Q & TS \\
\hline Freitas \& Ferreira (2013) & A & Elderly people; Old age & FAT & TS \\
\hline Gaymard \& Bordarie (2015) & $\mathrm{A} ; \mathrm{Ad}$ & Ideal neighbourhood & FAT & TS \\
\hline Goodwin et al. (2004) & $A$ & HIV/AIDS & Q; 1 & TS \\
\hline Harma et al. (2013) & A & Disability; Otherness & FAT & TS \\
\hline Joffe \& Battega (2003) & A & HIV/AIDS & Q; I & TS \\
\hline Kaiser (2004) & & Youth & & TC \\
\hline Kokurina \& Solina (2014) & $\mathrm{A} ; \mathrm{Ad}$ & Happiness; Life satisfaction & IS; FAT & TS \\
\hline Molinari et al. (2002) & $\mathrm{A} ; \mathrm{Ad}$ & Children's rights & FAT & TS \\
\hline Oliveira Arraes et al. (2013) & $\mathrm{A} ; \mathrm{Ad}$ & Masculinity; HIV/AIDS & 1 & TS \\
\hline Onwezen \& Bartels (2013) & $\mathrm{A} ; \mathrm{Ad}$ & New foods & Q & TS \\
\hline Roberts et al. (2007) & C; A & The war in Iraq & I & TS \\
\hline Roland-Lévy (2003) & A & The euro & $\mathrm{Q}$ & LS; TS \\
\hline Sarrica \& Wachelke (2009) & A & Peace and war & FAT & TS \\
\hline Stjerna et al. (2004) & A & Tobacco use & FG & TS \\
\hline
\end{tabular}

a Population codes: C, Children; A, Adolescents; Ad, Adults.

${ }^{b}$ Method codes: FAT, free-association test; FG, focus groups; I, interview; IS; incomplete sentence/association test; Q, questionnaire; SFS, Short film scenarios.

'Study design: TS, Transversal Study; TC, Theoretical Contribution.

Table 2. Characteristics of Works which Mention Theoretical Implications (TI) or Methodological Implication (MI) Associated to the Study of Srs in Children and/or Adolescents.

\begin{tabular}{|c|c|c|c|c|c|}
\hline Reference & Population $^{\mathrm{a}}$ & Object & Method $^{b}$ & Design $^{c}$ & $\mathrm{TI} / \mathrm{MI}$ \\
\hline Abreu \& Hale (2011) & $\mathrm{A} ; \mathrm{Ad}$ & Cultural identity & I & TS & $\mathrm{Tl}$ \\
\hline Archer \& Parker (1994) & $\mathrm{C}$ & Aggression & Q & LS & MI \\
\hline Augoustinos (1991) & $\mathrm{A} ; \mathrm{Ad}$ & Australian society & $\mathrm{Q}$ & TS & $\mathrm{Tl}$ \\
\hline Bertrand \& Roussiau (2002) & $\mathrm{C} ; \mathrm{A} ; \mathrm{Ad}$ & The "bistrot" & FAT & TS & $\mathrm{TI}$ \\
\hline Chafel \& Neitzel (2005) & C & Poverty & I & TS & MI \\
\hline D'Amore (2007) & $A$ & "Eating" and body & FAT; I; D; Q & TS & MI \\
\hline Dougherty et al. (1992) & C; A & National identity & D; FAT; I/Q & TS & $\mathrm{TI}$ \\
\hline Emler (1987) & & Socio-moral development & & $\mathrm{TC}$ & $\mathrm{TI}$ \\
\hline Galli \& Nigro (1990) & C & The radioactivity & $\mathrm{D} ; \mathrm{I}$ & LS; TS & $\mathrm{Tl}$ \\
\hline Gaymard (2014) & $\mathrm{A} ; \mathrm{Ad}$ & Work & FAT & TS & MI \\
\hline Haubl \& Liebsch (2009) & C & $A D[H] D$ & 1 & TS & MI \\
\hline Howarth (2002) & A & Brixton & FG & TS & $\mathrm{TI}$ \\
\hline Larrue et al. (2000) & A & Political, right and left & FAT & LS & $\mathrm{TI}$ \\
\hline Paty \& Lassare (2007) & $A$ & The violence & $\mathrm{Q}$ & TS & $\mathrm{TI}$ \\
\hline Petrillo \& Donizzetti (2005) & $\mathrm{A} ; \mathrm{Ad}$ & Minor child & Q & TS & $\mathrm{TI}$ \\
\hline Räty et al. (2012) & C & Intellectual competence & D & TS & MI \\
\hline Tapper \& Boulton (2000) & C & Aggression & Q & TS & MI \\
\hline Thornberg (2010) & C & Bullying & 1 & TS & MI \\
\hline Winther-Lindqvist (2012) & C & Social identity & O; D; I & LS & MI \\
\hline
\end{tabular}

a Population codes: $\mathrm{C}$, Children; A, Adolescents; Ad, Adults.

${ }^{\mathrm{b}}$ Method codes: D, Drawing; FAT, free-association test; FG, focus groups; I, interview; O, observation; Q, questionnaire.

'Study design: LS, Longitudinal Study; TS, Transversal Study; TC, Theoretical Contribution. 
Table 3. Characteristics of Works which Mention Both Theoretical Implications (TI) or Methodological Implication (MI) Associated to the Study of Srs in Children and/or Adolescents.

\begin{tabular}{|c|c|c|c|c|}
\hline Reference & Population $^{\mathrm{a}}$ & Object & Method $^{b}$ & Design $^{c}$ \\
\hline Bensalah et al. (2006) & C & Relational modes with peers & Q & TS \\
\hline Christakis \& Davou (1997) & C & Health and disease & I & TS \\
\hline Constans et al. (2003) & $\mathrm{C} ; \mathrm{A} ; \mathrm{Ad}$ & The intelligence & Q; I & TS \\
\hline Duveen (1996) & C & Gender & EO; SO; I & LS \\
\hline Ecalle (1999) & C & The reading & Q & LS \\
\hline Emler \& Ohana (1993) & & Distinctive research strategy & & TC \\
\hline Galli \& Nigro (1992) & C & Power & FAT; PAT; D; I & TS \\
\hline Ivinson (2000) & C & The curriculum & O; TP; I & TS \\
\hline Jovchelovitch (2013) & C & Public sphere & $\mathrm{D} ; \mathrm{O} ; \mathrm{I}$ & TS \\
\hline Lloyd \& Duveen (1993) & & Development of SRs & & TC \\
\hline Löfdahl \& Hägglund (2006) & C & Participation and power & $\mathrm{O}$ & LS \\
\hline Mannetti \& Tanucci (1993) & $\mathrm{C} ; \mathrm{A} ; \mathrm{Ad}$ & Work & Q; I & TS \\
\hline Molinari (2001) & A & Children's rights & FAT; Q & TS \\
\hline Psaltis (2012) & & Gender & & TC \\
\hline Rosa, de (1992) & & Developmental social cognition & & TC \\
\hline Thrush et al. (1997) & C & Smoking & Q & TS \\
\hline
\end{tabular}

a Population codes: C, Children; A, Adolescents; Ad, Adults.

b Method codes: D, Drawing; OE, ethnographic observation; FAT, free-association test; FG, focus groups; I, interview; O, observation; PAT, pair association task; Q, questionnaire; SO; structured observations; TP, task performance.

'Study design: LS, Longitudinal Study; TS, Transversal Study; TC, Theoretical Co

TI referred to: (a) the implication of SRs in the social context and the implication of socialization/social interaction ( $n=12)$; (b) links between the psychology of development and the theory of SRs ( $n=14)$; (c) the active role of children/adolescents in the creation of SRs ( $n=10)$; (d)the expression of SRs in the everyday actions of children/adolescents $(n=8)$; (e) the modification of SRs with children's/adolescents' development $(n=3)$; and $(f)$ the value of children/adolescents for studying the development of the theory of SRs $(n=3)$.

Concerning $\mathrm{MI}$, they referred to: (a) adaptation and precautions to be taken during the use of a method usually used with adults ( $n=9$ ); (b) the expression of SRs in everyday actions ( $n=7)$; and (c) the use of methods specific to (social/cognitive capacities of) children/adolescents $(n=8)$.

\section{Discussion}

The aim of this paper was to perform an ad hoc review of the existing literature concerning the study of SRs in children and adolescents in order to put forward theoretical-methodological proposals concerning the study and the development of SRs. Before discussing the contributions of this review, it seems necessary to point some limits. The first one concerns the fact that the review builds on only one database (i.e., PsycINFO), which limits the access to certain works. Besides, the SRs theory was also diffused and developed out of the psychology field (e.g., anthropology, sociology, medicine). The second limit concerns the criterion of the languages of publication (i.e., English and French). In spite of the fact that the language of diffusion of the scientific community is mainly English, and that French is the language of "origin" of the SRs theory, it is possible that the choice of these criteria implies the exclusion of relevant works (cf. Eicher, Emery, Maridor, Gilles, \& Bangerter, 2011).

\section{Study Characteristics}

The first report of our work concerns the relatively restricted number of references included in this review. Indeed, only $22.0 \%$ of the identified references were eligible. Moreover, if we compare it with reviews performed on the theory of SRs in a more general way (i.e., one which does not specifically refer to children and/or adolescents), the SRs study field in child and adolescent populations seems to occupy a relatively restricted position in the literature on SRs. For example, the research of Buschini and Lorenzi-Cioldi 
(2013) identified 643 references; another study led by Eicher and her colleagues (2011) on PsycINFO listed 997 reviewed articles published between 1970 and 2009. The relatively low number of studies on children may be linked to the complexity of data collection with this population. Furthermore, studies in children and adolescents are usually the hallmark of developmental psychology, which may explain why social psychologists have invested less this field. Sociogenesis and ontogenesis compete during the whole of the children's development period (Moscovici, 1995). Thus, due to the relevance of this population for studying the genesis and the development of the theory of SRs (Duveen \& Lloyd, 1990; Rouquette \& Garnier, 1999), it seems to us that researchers interested in SRs theory should pursue studies on children and/or adolescents more actively. As a matter of fact, it appears to be easier to study this genesis through "an arbitrary object created by very young children" than by the "representation of a social object that suddenly appears in society" (Rouquette \& Garnier, p. 87).

Concerning the geographic location of works, the results of this review show that the majority of the included studies were led in Europe and more specifically in France, Italy and Great-Britain. It highlights a limited spread of the SRs theory with regard to the study of the social construction of knowledge for child and teenage populations, in spite of the heuristic character of this theory and its potential complementarity to other approaches (i.e., developmental psychology) (cf. Lloyd \& Duveen, 1993). Those data may be explained by the fact that Europe is the "point of origin" of the SRs theory. However, as SRs are socially developed and shared, it seems important to conduct studies in a wide range of cultures. More specifically, studies must not be limited to Western cultures (i.e., individualist culture). As stated by Jovchelovicth and her colleagues (2013), individualism and collectivism, which can also co-exist in one particular culture, "constitute a context of representation, an already-there semiotic environment, in which children mature and come to know the world." (p. 326). Moreover, these "contexts of representation are cultural and inscribed in word meaning (Toomela, 2003), artefacts (Cole, 1996) and the development of knowledge (Duveen \& Lloyd, 1993; Jovchelovitch, 2007)" (Jovchelovitch, Priego- Hernández, \& Glăveanu, 2013, pp. 326-327). Thus, it could be relevant for the development of the theory of SRs to conduct studies on collectivistic cultures, and comparative studies between collectivistic and individualistic cultures.

\section{Objects of Study}

The results pointed out that a majority of objects of representations studied in the research included objects related to the field of health. This result is also found in other reviews which do not specifically refer to children and/or adolescents (Buschini \& Lorenzi-Cioldi, 2013). It is possible that health is particularly examined when studying children and adolescents because of the interest public health carries in the analysis of the risk behaviours of young people (e.g., food, bullying, pregnancy). This social stake partly joins a theoretical stake. Indeed, in an additional perspective, we can underline the complexity and the dynamics of the phenomena related to the study of the social construction of health and disease. These objects can constitute a favourable ground for the use of the SRs theory, which allows us to study the correspondence and the reciprocity of the perspectives between the order of ideas and the social order (cf. Apostolidis \& Dany, 2012). Health is also a particularly effective field for the use and the interchangeability of different types of knowledge (cf. Legare \& Gelman, 2008). Considering that all individuals face health issues, it seems relevant to study how health is represented by children, and how it is transmitted by their parents. Thus, it could lead us to study microgenesis, using an approach based on transmission via familial socialization.

Results also highlight the fact that a large part of the studied objects of SRs is included in the category "society, law, politics, and economy". To a lesser extent, we also find objects of representations inherent in the categories "identity", and "social relationships and their issues". Children are born in an "already there" social and representational world. SRs are also developed and shared through social interactions where transmission and knowledge building process are intertwined (Rouquette \& Garnier, 1999). "Children do not acquire [SRs] passively, as targets of the socialization process, but actively through negotiation (talking, interacting) with others." (Chafel \& Neitzel, 2005, p. 434). Thus, it seems necessary to study the interrelations between self-other-objects (see Jovchelovitch, 2007) through identity building, social relationships, and the child's understanding of the world (e.g., society) in which he/ she grows. The study of the social inclusion of children (and adolescents) as social agents seems necessary in order to understand the genesis of SRs. 


\section{Participants and Study Design}

A first remark to be made is that results show a certain lack of consensus concerning ages related to childhood and adolescence. Considering all the studies, children are 3-14 years old whereas adolescents are 11-20 years old. However, this difficulty to define a standardized age bracket characterizing children and adolescents is also found in the developmental psychology field. Indeed, the period of adolescence is bounded by criteria inherent to the biological, cognitive, emotional, legal, and social dimensions (Bideaud, Houdé, \& Pedinielli, 2011). In the field of SRs, it seems essential to develop more precise criterions for the definition of the studied populations on the basis of psychosocial components and of theoreticalmethodological relevance.

Concerning the study design, a large part of research included in the review of the literature contain samples of children and/or adolescents of identical ages. Hence, we can wonder if the design of studies does allow answering the important question of the genesis of SRs by studying a single sample age group. Studying the genesis of SRs implies being interested in the diachronic aspect of thought. In order to carry out a survey designed to examine the diachronic aspect of thought, the researcher can use longitudinal and transverse approaches (cf. Bideaud et al., 2011). Considered as the optimal methodology for studying developmental change, the longitudinal approach could be further developed in the field of the study of SRs in order to better understand the process of ontogenesis. The use of transverse approaches (i.e., comparative initiatives) could be particularly interesting for understanding the transition that occurs between childhood and adolescence. As stated by Molinari (2001), the period of adolescence is caught between two opposing forces. "On the one hand are the desires of the adolescent for autonomy and separation from parents. On the other, there are still fairly strong influences from the family, particularly in terms of principles and reference values." (Molinari, 2001, p. 242). Studying the change in the reference group (i.e., child to adolescent), allows us to study the question of the group, and therefore the identity, that is a central point of the SRs theory that is constantly discussed. SRs is thought to be the SRs of a particular group. However, the question of adolescents' identification with particular social groups is little or not at all considered outside their identification with the "adolescent" group. This consideration could lead to a certain homogeneity of possible identifications. As studies on adults rarely put forward their "adult" identity, it could be interesting to undertake studies on adolescents by taking into account their various identities.

Another interesting and important aspect highlighted by our review concerns the presence of the parents in the studies. According to Duveen and Lloyd (1990) "Human infants are born into a social world constructed in terms of the social representations of their parents, siblings, teachers, etc." (p. 7). The first social relations become established in the family and more particularly with the parents (e.g., Cartron \& Winnykamen, 2009). So, the socialization of the children is to be thought as collective and social phenomenon (cf. Corsaro, 2005). Even before children enter a practice or come to understand their identity (as boys or girls for example), parents and other members in the community have expectations for them (Duveen, 2001). Through their participation in the social life and the interactions with the adults (in particular with their parents) and their peers, the children internalize SRs conveyed in and by their group of membership. This internalization can be observed in the daily routines (e.g., role-play routines, routines to circumvent adult rules) (cf. Corsaro, 2005). The necessity of an approach in terms of familial socialization (i.e., including children-parents mixed samples) seems to constitute a major stake to study the phenomena of the genesis of SRs in children (i.e., ontogenesis), in link with the social construction of the world which their parents elaborated (i.e., sociogenesis) and which they contribute to transmit to their children (i.e., microgenesis).

\section{Methodological and Theoretical Implications}

The multi-methodological initiatives of research are relatively frequent in articles included in this review. "Methodological polytheism" is an important issue in the study of SRs (cf. Kalampalikis \& Apostolidis, 2016) because the use of a single methodology cannot satisfy the requirements of a study of SRs that aims to be holistic (Moscovici, 1961/1976). Results highlight, moreover, a wide range of methods used to study SRs in children and/or adolescents. The questionnaire is one of the most popular methods, used both with children and adolescents. Although they can be quickly designed and administered to many participants, questionnaires used with children need specific improvements in line with their cognitive skills (e.g., use of short, clear and unambiguous instructions, use of smileys and/or pictures for a better understanding of items) (cf. Greig, Taylor, \& MacKay, 2013; Molinari, 2001). Also, it seems necessary to provide an appropriate procedure like a child-appropriate 
setup (in order to avoid talking and copying between participants) and the possibility of helping participants (e.g., by reading items or answering questions) without directing their answers. Obviously, this kind of method requires a certain ability to read and write, which implies that it cannot be used with young children. In the same vein, the FAT is frequently used for the collection of SRs (cf. Dany, Urdapilleta, \& Lo Monaco, 2015) and presents a certain number of advantages that can explain his use with children and adolescents: it allows data produced from the free expression of individuals to be processed directly, it is quick to implement and analyse, and it is easy to use and understand (Abric, 2003). Indeed, this method (alone or with other techniques) was used to study relatively diverse and more or less abstract objects (e.g., power, politics, peace and war, eating and body, children's rights). However, it seems relevant to make participants contextualize (e.g., using contextualization phrase, interview, drawing) works/expressions that they produce in order to ensure that they are properly understood by researchers. This stage seems all the more necessary given that adults are trying to understand/analyse children'/ adolescents' point of view. As "children actively make sense of what is present in adult culture by interpreting its consequences and meaning in their own culture" (Löfdahl \& Hägglund, 2006, p. 181), the same words could lead to different meanings for children and adults. Results also showed that interviews are widely used with children and adolescents. This method could be very useful, especially if they are conducted by interviewers who know participants well (e.g., parents, teachers, carers), in order to obtain the children's own perspective (Greig et al., 2013). Yet, researchers must be aware that the nature of relationships between children and adults is usually an asymmetric relationship in the adult's favour (see Bensalah, Paty, \& Olivier, 2006). They must also keep in mind the co-constructive nature of interviews, which may complicate the distinction between the child's own representations and the impact of the interviewer/the interview context (cf. Thornberg, 2010). Hence, researchers must be cautious when leading and interpreting interviews with children. In a more limited way, focus groups were also used. However, focus groups are not suitable for children under 6 years old, because they do not have the social or language skills to be effective participants in group discussions (Heary \& Hennesy, 2002). Nevertheless, the technique of observation could be appropriate for young children (e.g., no need for the acquisition of language/writing/reading). This method allows us to study the object within its sociocultural context of production and to interact with its actors (cf. Buschini \& Lorenzi-Cioldi, 2013). For example, SRs could be expressed through play (cf. Duveen, 2006; Löfdahl \& Hägglund, 2006). Frequently used in research on the psychology of development (e.g., Cox, 2005), observation is little used for studying SRs. This report can explain to a certain extent the fundamental place occupied by communication and language in the theory of SRs (Moscovici, 2001). This method could be more developed in the field of SRs in particular by using it as support for linguistic production.

As stated by Moscovici (2003), "more account must be taken of researchers' creativity than of recipes" (p. 168) when it comes to methodology. That being said, researchers should therefore give themselves the opportunity to develop new methods of study (e.g., scripts/playing with dolls, drawing/pictures/ plasticine, stories) in keeping with the theoretical issues, the specificity of the population and of the object studied. The increase of new technologies (e.g., the Internet, video games) opens up many possibilities for research with children and adolescents (cf. Greig et al., 2013). Furthermore, it could be interesting to develop iconographic productions (e.g., pictures via smartphone). This method is in keeping with tasks expected from children, is usually developed as a classroom activity, and is more natural and less intimidating than a face-to-face interview with an adult.

As children are fully fledged social agents, their SRs must be considered as autonomous although they result from sociogenesis and socialization. They are autonomous in the sense that they convey children's own knowledge and meanings. There is some value in overcoming a strictly developmental view that consists of seeing acquisition steps in terms of stages. Hence, children's SRs should be considered per se and not as incomplete adult production (see Jovchelovitch et al., 2013). In order to adjust methods and data processing to children, it could be interesting to consider the child as a researcher (Murray, 2015) and not only as a participant. For example, analysing data with children may ensure an effective understanding from researchers. Finally, it could be relevant to build on (without being restricted to) the knowledge of developmental psychology in order to understand how knowledge is constructed and transmitted to children and adolescents (see Duveen, 2001; Molinari, 2001). The link between these two disciplines may also allow us to develop useful methods whilst taking into account the specificities of children. 


\section{Summary and Implication for Research}

The various contributions included in this review of the literature enabled us to establish a representative situation, although not exhaustive, of the current knowledge concerning the study of SRs in children and adolescents. Despite the value and the pertinence of the theoretical developments and proposals associated with the question of the genesis and the development of SRs, we can observe the absence of an integrative global view that could permit us to determine the processes and the mechanisms involved. This conclusion underlines the necessity for deeper development of theoretical-methodological reflections on this issue (e.g., the genesis and development of SRs, the link between psychology of development and SRs, children as social agent per se, the development of methods suitable for children and the transmission of SRs via family socialization). It also seems to us that the empirical studies carried out on children and adolescents could establish a heuristic option for the study of the construction and the development of SRs (Rouquette \& Garnier, 1999).

\section{References}

Abric, J.-C. (1994). Pratiques sociales et représentations [Social practices and representations]. Paris: Presses Universitaires de France.

Abric, J.-C. (2003). Méthodes d'études des représentations sociales [Method of studies of social representations]. Ramonville Saint Agne: Erès.

Apostolidis, T., \& Dany, L. (2012). Pensée sociale et risques dans le domaine de la santé: le regard des représentations sociales [Social thought ad risks in the health field: the social representations perspective]. Psychologie Française, 57, 67-81. doi: 10.1016/j. psfr.2012.03.003

Bensalah, L., Paty, B., \& Olivier, M. (2006). Représentations des modes relationnels avec leurs pairs par des enfants de 7 à 10 ans [Representations of modes of relating with peers by children from 7 to 10 years old]. Enfance, 58(4), 357-376. doi: 10.3917/enf.584.0357

Bideaud, J., Houdé, O., \& Pedinielli, J. L. (2011). L'homme en développement [The developing human] $\left(7^{\text {th }}\right.$ ed.). Paris: Presses Universitaires de France.

Buschini, F., \& Lorenzi-Cioldi, F. (2013). Représentations sociales [Social representations]. In L. Bègue \& O. Desrichard (Eds.), Traité de psychologie sociale (pp. 395-415). Bruxelles: De Boeck.

Cartron, A., \& Winnykamen, F. (2009). Les relations sociales chez l'enfant: genèse, développement, fonction [Social relations in children: genesis, development, function]. Paris: Armand Colin.

Chafel, J. A., \& Neitzel, C. (2005). Young children's ideas about the nature, causes, justification, and alleviation of poverty. Early Childhood Research Quarterly, 20, 433-450. doi: 10.1016/j. ecresq.2005.10.004
Cole M. (1996). Cultural psychology: A once and future discipline. Cambridge: Harvard University Press.

Corsaro, W. (2005). The sociology of childhood ( $2^{\text {nd }}$ ed.). Thousand Oaks: Pine Forge Press.

Cox, M. (2005). The pictorial world of the child. Cambridge: Cambridge University Press.

Dany, L., Urdapilleta, I., \& Lo Monaco, G. (2015). Free associations and social representations: some reflections on rank-frequency and importance-frequency method. Quality \& Quantity, 49, 489-507. doi: 10.1007/s11135-014-0005-z

Doise, W. (1988). Les représentations sociales : un label de qualité [Social representations: a quality label]. Connexions, 51, 99-113.

Durkheim, É. (1967). Représentations individuelles et représentations collectives [Individual representations and collective representations]. In É. Durkheim (Ed.), Sociologie et Philosophie (pp. 1-48). Paris : Presses Universitaires de France. (Original work published 1898)

Duveen, G. (1996). The development of social representations of gender. The Japanese Journal of Experimental Social Psychology, 35(3), 256-262. doi: 10.2130/jjesp.35.256

Duveen, G. (2001). Representations, identities, resistance. In K. Deaux \& G. Philogène (Eds.), Representations of the social (pp. 257-270). Oxford: Blackwell.

Duveen, G. (2006). Introdução: o poder das ideias. In S. Moscovici (Org.), Representações sociais: investigações em Psicologia Social (pp. 7-28) (P. A. Guareschi, Trad.). R.J.:Vozes. (Trabalho original publicado em 2000).

Duveen, G., \& Lloyd, B. (1990). Social representations and the development of knowledge. Cambridge: Cambridge University Press.

Duveen G., \& Lloyd B. (1993). The development of social representations. In: Pratt C., Garton A. (Eds) Systems of representations in children: Development and use (pp. 167-183). New York: John Wiley \& Sons,

Eicher, V., Emery, V., Maridor, M., Gilles, I., \& Bangerter, A. (2011). Social representations in psychology: a bibliometrical analysis. Papers on Social Representations, 20,11.1-11.19. Retrieved from http://www.psych.Ise.ac.uk/psr/

Greig, A., Taylor, J., \& MacKay, T. (2013). Doing research with children a practical guide ( $3^{\text {rd }}$ ed.). London: SAGE Publications.

Haubl, R., \& Liebsch, K. (2009). « My mother thinks that this is the case, and so does my teacher. I, for my part, do not notice any difference „: methodological reflections on intersubjectivity in the research process with children. Journal of Social Work Practice, 23(2), 229-241. doi: 10.1080/02650530902923890

Heary, C. M., \& Hennessy, E. (2002). The use of focus group interviews in pediatric health care research. Journal of Pediatric Psychology, 27(1), 47-57. doi: 10.1093/jpepsy/27.1.47

Jodelet, D. (1989). Folies et représentations sociales [Madness and social representations]. Paris: Presses Universitaires de France.

Jovchelovitch, S. (2007). Knowledge in context: representations, community and culture. London: Routledge.

Jovchelovitch, S., Priego- Hernández, J., \& Glăveanu, V. P. (2013). Constructing public worlds: culture and socio-economic context in the development of children's representations of the public sphere. Culture \& psychology, 19(3), 323-347. doi: 10.1177/1354067X13489320

Kalampalikis, N., \& Apostolidis, T. (2016). La perspective socio-génétique des représentations sociales [The socio-genetic view of social 
The study of social representations in children and adolescents: Lessons from a review of the literature

representations]. In G. Lo Monaco, S. Delouvée, \& P. Rateau (Eds.), Les représentations sociales (pp. 69-84). Bruxelles: De Boek.

Karmiloff-Smith, A. (1979). A functional approach to child language. Cambridge: Cambridge University Press.

Legare, C. H., \& Gelman, S. A. (2008). Bewitchment, biology, or both: the co-existence of natural and supernatural explanatory frameworks across development. Cognitive

Science, 32(4), 607-642. doi: 10.1080/03640210802066766

Lloyd, B., \& Duveen, G. (1992). Gender identities and education: the impact of starting school. London: Harvester-Wheatsheaf.

Lloyd, B., \& Duveen, G. (1993). The development of social representations. In C. Pratt \& A. Garton (Eds.), Systems of representation in children: development and use (pp. 167-183). Oxford: John Wiley \& Sons.

Löfdahl, A., \& Hâgglund, S. (2006). Power and participation: social representations among children in pre-school. Social Psychology of Education, 9, 179-194. doi: 10.1007/s11218-006-0002-8

Molinari, L. (2001). Social representations of children's rights: the point of view of adolescents. Swiss Journal of Psychology, 60(4), 231243. doi: 10.1024//1421-0185.60.4.231

Moscovici, S. (1973). Foreword. In C. Herzlich (Ed.), Health and illness (pp. ix-xiv). London: Academic Press.

Moscovici, S. (1976). La Psychanalyse son image et son public [Psychoanalysis: Its image and its public] ( $2^{\text {nd }}$ ed.). Paris: Presses Universitaires de France. (Original work published in 1961)

Moscovici, S. (1995). Vygotsky, le Grand Robert et la cyber-représentation [Vygotsky, Grand Robert and public cyber-representation]. Les Cahiers Internationaux de Psychologie Sociale, 28, 15-21.
Moscovici, S. (1998). The history and actuality of social representations. In U. Flick (Ed.), The psychology of the social (pp. 18-61). Cambridge: Cambridge University Press.

Moscovici, S. (2001). Why a theory of social representations? In K. Deaux \& G. Philogène (Eds.), Representations of the social (pp. 18-61). Oxford: Blackwell Publishers.

Moscovici, S. (2003). O fenômeno das representações sociais. In S. Moscovici (Ed.), Representações sociais: investigações em psicologia social (pp. 29-109). Petrópolis: Vozes

Moscovici, S., \& Duveen, G. (2000). Social representations. Explorations in social psychology. Cambridge: Cambridge University Press.

Murray, J. (2015). Can young children be researchers? In H. McLaughlin (Ed.), Children and young peoples participation in policy, practice and research (pp. 48-63). London: National Children's Bureau.

Perner, J. (1991). Understanding the Representational Mind. Cambridge: MIT Press.

Rouquette, M.-L., \& Garnier, C. (1999). La genèse des représentations sociales [The genesis of social representations]. Montréal, Québec: Éditions Nouvelles.

Toomela A. (2003). Cultural guidance in the development of the human mind. Westport, CT: Ablex Publishing.

Thornberg, R. (2010). School children's social representations on bullying causes. Psychology in the Schools, 47(4), 311-327. doi: 10.1002/pits.20472

Wagner, W., \& Hayes, N. (2005). Everyday discourse and common sense. The Theory of Social Representations. Hampshire: Palgrave.

Marie-Anastasie Aim, PhD. Student (Social Psychology) at Aix Marseille University (AMU), LPS, Aix-en-Provence, France. Address: Laboratoire de Psychologie Sociale (LPS), Aix-Marseille Université, 29 avenue Robert Schuman, 13621 Aix-en-Provence, France. Telephone: 0033683762417. E-mail address: marieana.aim@gmail.com

Véronique Goussé, Associated Professor at Nîmes University (UNîMES). E-mail address: veronique.gousse@unimes.fr

Thémistoklis Apostolidis, Professor (Social Psychology) Aix Marseille University (AMU), Laboratoire de Psychologie Sociale (LPS), Aix-enProvence, France.

E-mail address: themistoklis.apostolidis@univ-amu.fr

Lionel Dany, Professor (Social Psychology) Aix Marseille University (AMU), Laboratoire de Psychologie Sociale (LPS) E-mail address: lionel.dany@univ-amu.fr

Recebido em 10.Set.15 Revisado em 05.Out.16 Aceito em 27.Mar.17 